\title{
Metastatic Nasopharyngeal Undifferentiated Carcinoma
}

National Cancer Institute

\section{Source}

National Cancer Institute. Metastatic Nasopharyngeal Undifferentiated Carcinoma. NCI Thesaurus. Code C156078.

An undifferentiated carcinoma that arises from the nasopharynx and has metastasized to another anatomic site. 